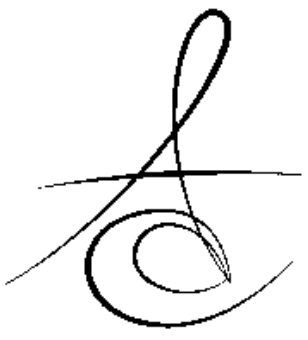

\title{
LARİNGEAL SKUAMOZ HÜCRELİ KANSERLİ HASTADA POSTOPERATİF RADYOTERAPİ SONRASINDA SABİT-HAREKETLİ DENTAL PROTEZ TEDAVİSİ: VAKA RAPORU
}

\author{
PATIENT WITH LARYNGEAL SQUAMOUS CELL CANCER AFTER \\ POSTOPERATIVE RADIATION THERAPY FIXED-REMOVABLE DENTAL \\ PROSTHESIS: A CASE REPORT
}

\author{
Uzm. Dt. Hatice AĞAN* \\ Doç. Dr. Rukiye DURKAN***
}

\author{
Prof. Dr. Ayhan GÜRBÜz* ${ }^{* *}$ \\ Dr. Öğr. Üyesi Gonca DESTE ${ }^{* * *}$
}

Makale Kodu/Article code: 3121

Makale Gönderilme tarihi; 08.11.2016

Kabul Tarihi: $\quad 09.12 .2016$

\section{öz}

Laringeal squamoz hücreli kanserlerin tedavisinde transoral lazer cerrahisi, radyoterapi, kemoterapi veya bu tedavilerin kombinasyonları kullanılmaktadır. Yüksek doz raduoterapi uygulandığı zaman bu durum hastanın oral sağlığını etkileyebilmektedir. Radyasyon tedavisinin yan etkileri mukozit, tükürük bezlerinde fonksiyon değişiklikleri ve mukozal infeksiyon risklerinin artmasını içermektedir. Kserostomi boyun radyoterapileri sonunda yaygın gözlenen önemli bir sonuçtur. Tükürük kaybına bağlı olarak gelişen kserostomide rampant kariesler, bakterial infeksiyonlar ve periodontal hastalıklara yatkınlık oluşmaktadır. Bu istenmeyen yan etkiler hastanın yaşam kalitesini olumsuz etkilemektedir. Bu vaka raporunun amacl; Laringeal squamoz hücreli kanserden dolayı parsiyel laringektomi ve bilateral boyun diseksiyonu kanser cerrahisi geçiren ve post operatif radyoterapi gören hastanın sabit ve hareketli dental protezler ile tedavisi sunulmaktadır.

Anahtar Kelimeler: laringeal skuamoz hücreli kanser, radyoterapi, sabit ve hareketli dental protezler, rampant karies

\section{ABSTRACT}

Transoral endoscopic laser surgery, radiotherapy, chemotheraphy or combination of these are used in the management of laryngeal squamous cell cancers. When the neck tissues are exposed to high doses of radiation, this may affect the patient's oral health. The side effects of radiation therapy include mucositis, altered salivary gland function and risk of mucosal infection. Xerostomia is a common and significant consequence of neck radiotherapy. Because of the loss of saliva, patients with xerostomia are more susceptible to periodontal disease, bacterial infections and rampant caries. These undiserable side effects can adversely affect patients' life quality. The aim of this case report is to the fabrication of fixed and removable dental prosthesis for a patient with laryngeal squamous cell cancer because of partial laryngectomy and bilateral functional neck dissection cancer surgery and postoperative radiotherapy.

Keywords: laryngeal squamous cell cancer, radiotherapy, fixed and removable dental prosthesis, rampant caries

\footnotetext{
*Serbest Diş Hekimi, Acıbadem, İstanbul

** Ankara Üniversitesi Diş Hekimliği Fakültesi, Protetik Diş Tedavisi Anabilim Dalı, Ankara

${ }^{* * *}$ Afyonkarahisar Sağılık Bilimleri Üniversitesi Diş Hekimliği Fakültesi, Protetik Diş Tedavisi Anabilim Dalı, Afyon
} 


\section{GİRİ̧̧}

\%90-95 oranında epidermoid squamoz hücreli olan laringeal kanserler tüm kanserlerin \%10-15'ini oluştururlar. ${ }^{1}$ 50-60 yaş düzeyinde erkeklerde ve sosyoekonomik düzeyi düşük bireylerde daha sık rastlanmaktadır. ${ }^{2}$ Alkol, sigara, duman, buhar ve irritan maddelere maruz kalma etiyolojisinde önemli olan predispozan faktörlerdir. ${ }^{3,4}$

Laringeal kanser tedavilerinde gelinen son noktada transoral endoskobik lazer cerrahisi (TLS), foto dinamik tedavi (PDT), radyasyon tedavisi (RT), kemoterapi (CT) laringeal kanserlerde açık cerrahiye oranla daha çok kullanılan yöntemlerdir., ${ }^{5,6}$ Böylece daha düşük morbidite, yüksek oranda laringeal koruma, laringeal fonksiyonların devamı ile hastaların hayat kalitesi artmaktadır. ${ }^{6-8}$

Cerrahi sonrasında, eksternal ya da internal olarak uygulanabilen laringeal radyoterapi yaygın kullanılan bir yöntemdir. Çünkü iyonize radyasyon tekrarlayan kanser hücrelerinin yapısını bozar ve hücre ölümüne sebep olur. ${ }^{9,10}$

Rothwell, bilateral olarak uygulanan <45 Gy radyasyon dozuna bağlı olarak orafasiyel komplikasyonların olabileceğini ve bunların ağız, çeneler ve tükürük bezlerini etkileyebileceğini belirtmiştir. ${ }^{11}$

Laringeal radyoterapide tümörlü dokuların parçalanması sağlanırken ortamdaki radyasyon çevre dokuların özellikle ağız dokularının tolerans limitini aşar ve sağlıklı dokular radyasyondan olumsuz etkilenebilir. ${ }^{2,12}$ Radyoterapinin neden olduğu lokal doku değişiklikleri sonucu ağızda erken ve geç yan etkiler görülebilir. ${ }^{2,10}$ Radyasyonun yan etkileri özellikle çevre dokularda tedavi sonrası birinci haftada başlar. Dental hasarların oluşması ise $12-18$ aylık period sonunda oldukça fazladır. ${ }^{13}$

Radyasyon sonrası oluşacak en temel problem kuru ağız ve buna bağlı gelişen rampant çürükler ve oral infeksiyonlardır. ${ }^{14}$ Kuru ağızda salyanın hem nicelik hem de niteliği etkilenmiştir. Salya üretiminin azalması oral kavitenin $\mathrm{pH}^{\prime}$ sını, tamponlama kapasitesini, mikrobiyal dengeyi ve yeni başlayan çürüklerin remineralizasyonunu değiştirerek doğal korunma mekanizmasını zayıflatmıştır. ${ }^{15,16}$ Tükürüğün temizleyici etkisi ortadan kalkar ve bakterilere karşı koruyucu görevini yerine getiremez. ${ }^{13,17}$

Orafaringeal mukozitler, saliva kompozisyonundaki değişiklikler, deskuamasyon, periodontal ağrı ve ülserasyonlar, eritem, şişlik, ağrı, tükürük bezlerindeki fonksiyonun azalması, buna bağı infeksiyonlar (bakteriyal, fungal ve viral), tad alma bozuklukları (disgezi-dysguesia) ve tat kaybı erken dönemde görülen yan etkilerdir. ${ }^{5,18}$

Trismus ve fibrozis, kseratomi, dental çürükler, epitelyal atrofi, keratinizasyonun azalması, malnutrisyon, mukozada telenjektaziler geç dönem yan etkiler arasındadır. ${ }^{2,18}$ Yine bu dönemde osteoradyonekroz riski artmış, yara iyileşmesi gecikmiş, kemik dokusunun yeniden şekillenme yeteneği ve pulpal cevap azalmıştır. ${ }^{13}$ Diş dokularındaki harabiyete bağlı ağrı, enfeksiyon ve fonksiyon kaybı oluşabilir. Bu dönemde hastalar mevcut protezlerini özellikle de alt hareketli protezlerini kullanmakta zorluk çekerler. ${ }^{16}$ Oral florada görülen bu değişiklikler radyoterapiyi takiben 4 yıl kadar devam edebilir. ${ }^{19}$

Laringeal kanser sonrası radyoterapi gören hastalarda dental tedaviler yapılması özellikle hastaların fonksiyonel olarak beslenme, konuşma, estetik ve doku bütünlüğü ile psikolojik destek açısından zorunlu hale gelmektedir. ${ }^{13,16}$

$\mathrm{Bu}$ vaka raporunun amacl; laringeal squamoz hücreli kanserden dolayı parsiyel laringektomi ve bilateral boyun diseksiyonu geçiren ve postoperatif radyoterapi gören 53 yaşındaki erkek hastanın sabit ve hareketli dental protezler ile tedavisinin yapılmasıdır.

\section{OLGU SUNUMU}

53 yaşında sosyoekonomik düzeyi düşük olan erkek hasta Ankara Üniversitesi Diş Hekimliği Fakültesi Protetik Diş Tedavisi Anabilim dalına radyoterapi sonrası bütün dişlerinde gözlenen çürükler, bozulmuş ağız hijyeni ve ağrı şikayetleri ile gelmiştir. Hastanın medikal anamnezinde, 2014 yılında laringeal skuamoz hücreli kanser nedeni ile parsiyel laringektomi ve bilateral fonksiyonel boyun diseksiyonu ameliyatı geçirdiği öğrenilmiştir. Operasyonlardan sonra 6 hafta boyunca haftada 5 defa $15 \mathrm{dk}$ olacak şekilde boyun bölgesinden radyoterapi tedavisi (64 Gy-70 Gy, 32-35 defa günlük doz 1.8-2.0 Gy/fraction) yapıldığı belirlenmiştir.

Radyoterapi sonrasında 1,5 yıl sonra kliniğimize gelen hastada oral mukazada iyileşme tam sağlanmış ancak dişlerde radyasyon çürükleri gözlenmiştir.

Hasta boyun diseksiyonuna bağlı olarak konuşamadığından yazılı olarak iletişim kurularak bilgilen- 
dirilmiş onam formu alınmıştır. Hastaya kanser teşhisinin ardından ve tedavi süresince oral hijyen eğitimi verilmemiş olduğundan ve koruyucu önlemler alınmadığından oral hijyeni bozulmuştur.

Klinik muayenede hastanın her iki çenede molar dişlerini kaybettiği ve mevcut dişlerin özellikle servikal bölgelerinde radyasyon çürüklerinin varlı̆ı̆ı tespit edilmiştir. (Şekil 1) Klinik olarak dişlerde ciddi ağrılar, palpasyon ve perküsyonda hassasiyetler gözlenmiştir. Gingivitis ve oral hijyen eksikliği tespit edilmiştir. Radyolojik muayenede pulpaya ulaşan derin çürükler tespit edilmiştir. (Şekil 2)

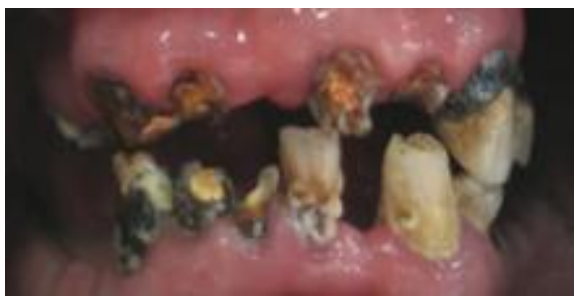

Şekil 1. Dental tedaviler öncesinde intraoral görünüm

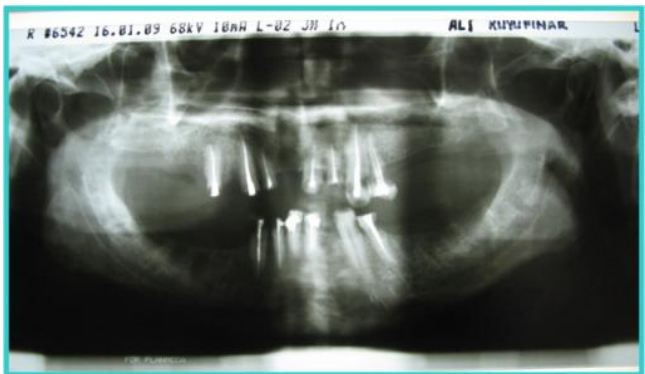

Şekil 2. Dental tedavilerde alınan radyografi

Hastanın tedavisindeki hedefler; dental ağrılarının giderilmesi, yeni çürüklerin oluşumunun engellenmesi, sağlıklı diş dokularının korunması, uygun fonksiyonel oklüzyonun sağlanması, kaybedilen estetiğin geri kazandırıması ve oral hijyen eğitimi ile bu koşulların idame edilmesine yönelik olmuştur. Dişeti tedavilerinin ardından, dişlerdeki çürükler tedavi edilerek 15,13,12, $21,22,23,24,33,32,31,41$ ve 44 numaralı dişlere kanal tedavileri yapılmıştır. 43 numaralı dişe kompozit dolgu (Filtek Z 250, 3M Espe, St. Paul, MN, USA) yapılmıştır. Aşırı madde kaybı görülen $15,13,12,21,22$ ve 24 no'lu dişlere metal döküm post, mandibuler kesici dişlere $33,32,31,41$ ve 44 no'lu dişlere ise prefabrike fiber
(Glassix, Harald Nordin SA, Chailly- Montreux, Switzerland) post uygulanmışıı. (Şekil 3) Dişler birbirlerine splintlenerek tek parça metal destekli porselen köprüler yapıımıştır. (Şekil 4) Daimi simantasyon öncesi dişlere topikal flor jel uygulanmıştı. Posterior diş eksikliklerinin giderilmesi için iskelet bölümlü hareketli protezler yapıımışııı. (Şekil 5)

Hastaya oral hijyen eğitimi verilmiş ve 24 saat sonra kontrol randevusuna çağırılmıştır. Gereken düzeltmelerin ardından 3 gün sonrasına randevu verilmiştir. Oral hijyen kuralları tekrar edilmiştir. Bir yıl sonra hastanın muayenesinde oral sağlı̆ının yeterli olduğu protezlerde herhangi bir problem olmadığı gözlenmiştir. (Şekil 6) Ayrıca hastanın kanser kontrollerinde herhangi bir olumsuzluk olmadığı belirlenmiştir.

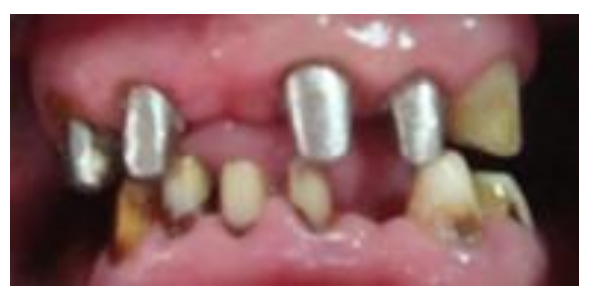

Şekil 3. Metal döküm post ve prefabrike fiber post uygulandıktan sonra görünüm

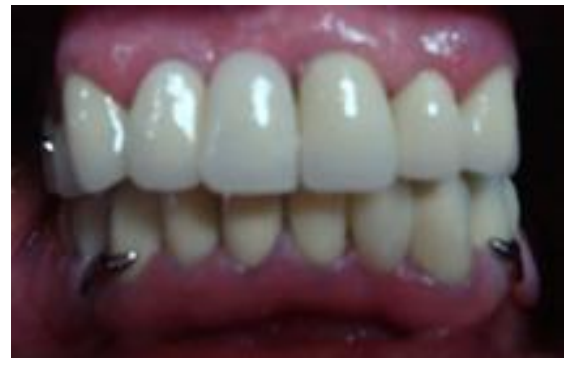

Şekil 4. Anterior dişlere yapılan metal destekli porselen sabit protez

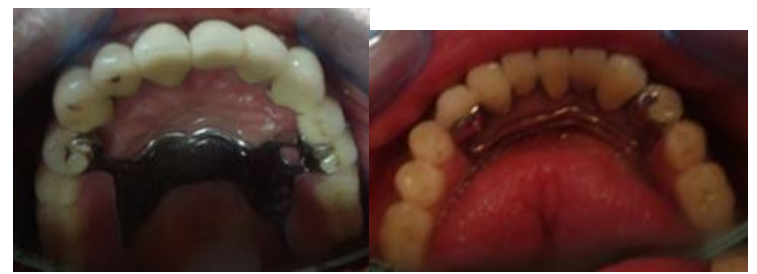

Şekil 5 . Posterior dişsiz kretlerde uygulanan hareketli parsiyel protezler 


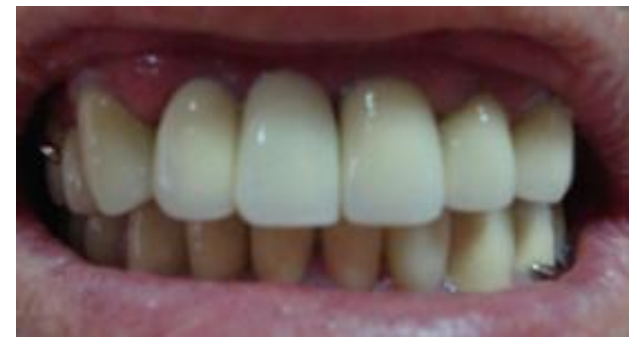

Şekil 6. Kontrol seansında protezlerin görünümü

\section{TARTIŞMA}

Laringeal kanserlerde ve diğer baş-boyun kanserlerinde radyoterapi tedavisi öncesinde oral hijyen sağlanması ve gerekli dental tedavilerin yapılması oldukça önemlidir. ${ }^{3,20}$ Hastalar düzenli olarak dental tedaviler ve oral hijyen bakımından kontrol edilmelidir. Ancak genellikle bu göz ardı edilmekte ve hastalar radyoterapi sonrasında ağızlarında pek çok dental sorun olduğu zaman dental kliniklere yönelmektedirler. Orodental komplikasyonlar olmadan önce oral sağlık bakımları yapılması gereklidir. ${ }^{13} \mathrm{Bu}$ vaka raporunda hasta laringeal kanser tedavileri ve radyoterapi sonrasında 2 yıl sonra kliniğe başvurmuştur. Bu nedenle mevcut durum değerlendirilerek radyasyon tedavisine bağlı gelişen oral komplikasyonlar, bunların önlenmesi ve tedavisi ile ilgili bilgiler derlenmiştir.

Çiğneme kaslarında trismus olması ve ağız irritasyonları radyoterapinin sonrasında gözlenen erken ağız yan etkileri olduğu için protetik tedavilerin radyoterapiden en az 6 ay sonra yapılması önerilmektedir. ${ }^{16}$ Protezlerde monoplan dişler kullanılması önerilir. Vertikal boyutu düşük ve serbest aralık (freeway space) azdır. Doku irritasyonu olmaması için protez kenar (flange) uzantıları dikkatli kontrol edilmelidir. Radyoterapi gören hastalarda erken dönemde döküm post-core restorasyonlar önerilmemekle birlikte radyoterapi sonrasında 2 yıl geçtiği zaman bu tedaviler uygulanabilir. ${ }^{13}$

Protetik tedavi seçenekleri arasında olan implant tedavisi için radyoterapinin tipi, dozu, uygulama aralıkları (fractionation), reküren riskleri, implant uygulanması için anatomik bölgelerin tespiti, radyoterapi sonrasında implant uygulama zamanı önemli olmaktadır. Özellikle implant tedavilerinde radyoterapi sonrasında en az 1 yıl geçmesi gerektiğini belirten araştırmacılar bulunmaktadır. ${ }^{13,19}$ Hastada radyoterapi sonrasında 2 yıl geçtiği için implant tedavisi önerilmesine rağmen sosyoekonomik düzeyinden dolayı implant tedavisi yapılamamıştır.

Baş-boyun kanserleri sonrasında radyoterapi gören hastalarda kanıta dayalı oral sağlık protokolünde; her 3-4 ayda bir düzenli olarak dental muayene yapılması, oral hijyenin yüksek düzeyde sağlanması ve sürdürülmesi, plak ve gingival indexlerin azaltılması, çürük insidansının azaltılması, florlu ürünlerin kullanıması, klorhekzidin oral gargara ve ağız duşlarının kullanılması önemlidir. Spesifik dental sorunların tedavi edilmesi (proflaksiler, kazıma ve kök yüzeylerinin düzenlenmesi, dental çürükler, protezler, hipersensitivite) radyoterapiden önce tamamlanmalıdır. ${ }^{13}$

Diş çekimlerinin radyoterapiden 6-12 ay önce yapılması önerilmektedir. Radyoterapi sonrasında osteoradyonekrozun önlenmesinde hiperbarik oksijen tedavileri çene kemiklerine uygulanabilir. Ayrıca eğer ostoradyonekroz gelişmiş ise nekrotik dokuların temizlenmesini takiben postoperatif olarak 10 gün hiperbarik oksijen tedavisi ile çene kemiklerinde maksimum iyileşme sağlandığı belirtilmektedir. Radyoterapiye bağlı gelişen trismus olduğu zaman mandibuler kas egzersizleri önerilmektedir. ${ }^{21}$ Radyoterapi sonrasında 1-2 yıl sonra yapılabilecek implant uygulamalarında kemik yara iyileşmesi ve osseointegrasyonun yeterli olması için yükleme öncesinde uzun dönem beklenmesi gerekmektedir. ${ }^{13}$

Amerikan klinik onkoloji birliği (the American Society of Clinical Oncology) tarafından tedavi önerileri ve hayat kalitesini arttırmak için öneriler olarak sunulan birtakım tedbir ve tedavi yöntemleri bulunmaktadır. $^{2,10}$ Radyoterapiye bağlı olarak gelişen tükürük bezlerindeki fonksiyon bozuklukları ve tükürük azalmasının önlenmesi için sitoprotektif ajanlar (cytoprotective agents), tükürük artışını sağlamak için pilokarpin ve sevimelin gibi kolinerjik muskorinik agonistler (cholinergic muscarinic agonists-pilocarpine, cevimeline) ve submandibular tükürük bezlerinin cerrahi olarak tarnsfer edilmesi gibi yöntemler önerilmektedir. 22

Baş-boyun kanser radyoterapi tedavisi sonrasında \%20 oranında ilk 7 haftada tükürük akış hızı ve miktarı azalmaktadır. Azalan tükürük radyoterapinin dozuna bağı olarak kalıcı hale gelebilmektedir. Ortalama doz 40 Gy üzerinde olduğu zaman tükürük bezlerinin kapasitesi sınırlanmaktadır. ${ }^{23}$

Tükürük azalması olan kserastomide ilk tedavi 
yaklaşımı palyatif olmaktadır. Semptomları minimalize etmek ve oral komplikasyonları önlemek en önce yapılması gerekenlerdir. Ayrıca kserastomiyi elimine edebilecek faktörlere uymak gerekmektedir. Bunlar: alkol içeren ağız gargaraları kullanmamak, diyet şekerden uzak durmak, alkol sigara ve tütün gibi toksik alışkanlıkları bırakmak en önemli faktörlerdir. ${ }^{24}$

Tükürük akışını sağlamak ve arttırmak için klinik bakım ürünleri ve ilaçlardan faydalanmak gerekir. Sialojik ilaçlar (sialogogic drugs), immünolojik ajanlar (immunologic agents), topikal medikasyon, tamamlayıcı ve alternatif ilaçlar (complementary and alternative medicine) kullanılabilir. ${ }^{25-27}$

\section{SONUÇ}

Baş-boyun kanserlerinden, laringeal kanser cerrahisi sonrasında radyoterapi gören hastaların oral rehabilitasyonlarında hekimler azami özeni göstermelidir. Bu tür vakalarda konservatif protetik tedaviler tercih edilerek hastaların estetik, fonksiyon, fonasyon ve psikolojik ve doku bütünlüğü ile diğer beklentilerinin karşılanması son derece önemlidir. Kombine protetik tedavilerden önce iyi bir ağız hazırlığı ve oral hijyenin sağlanması gerekmektedir. Bu tür vakalarda kserostomi en önemli sorunlardan birisidir. Protetik tedavinin kısa sürede yapılarak tükürük artırıcı yöntemler hastalara sunulmalıdır. Hastaların sosyo ekonomik düzeylerine ve beklentilerine cevap verebilecek geniş yelpazede olan protetik tedaviler hastalara sunularak onamları alındıktan sonra hastaya ve hastalığa en uygun tedavi tercih edilmelidir. Ayrıca baş-boyun kanser cerrahisi ve radyoterapi gören hastalarda nüks ihtimali ve hastaların psikolojik durumları göz önünde bulundurulmalıdır. Çünkü yapılan tedavilerin başarılı olması hastaların bu tedaviye intiyaçlarının düzeyi ve protetik kabul ve hijyen koşullarına uymalarına bağlıdır.

Hatice Ağan: ORCID ID: 0000-0002-5287-774X

Ayhan Gürbüz: ORCID ID: 0000-0003-4066-9609

Rukiye Durkan: ORCID ID: 0000-0002-3381-4073

Gonca Deste: ORCID ID: 0000-0002-5481-0063

\section{KAYNAKLAR}

1. Beuer Li P, Hu W, Zhu Y, Liu J. Treatment and predictive factors in patients with recurrent laryngeal carcinoma: A retrospective study Oncology Letters 2015;10:3145-52.
2. Devi S, Singh N. Dental care during and after radiotherapy in head and neck cancer. National J Maxillofac Surg 2014;5:117-24.

3. Ward MC, Reddy CA, Adelstein DJ, Koyfman SA. Use of systemic therapy with definitive radiotherapy for elderly patients with head and neck cancer: A national cancer data base analysis. Cancer 2016;122:3472-83.

4. Lee DH, Kim SY, Nam SY, Choi SH, Choi JW, Roh JL. Risk factors of surgical site infection in patients undergoing major oncological surgery for head and neck cancer. Oral Oncol 2011;47:528-31.

5. Mendenhall WM, Dagan R, Bryant CM, Amdur RJ, Mancuso AA. Definitive Radiotherapy for Squamous Cell Carcinoma of the Glottic Larynx. Cancer Control 2016;23:208-12.

6. Silver CE, Beitler JJ, Shaha AR, Rinaldo A, Ferlito A. Current trends in initial management of laryngeal cancer: the declining use of open surgery. Eur Arch Otorhinolaryngol 2009;266:1333-52.

7. Yang $Y$, Wang $T$. Radiotherapy of the neck and carotid stenosis. J Biol Regul Homeost Agents 2016; 30:795-9.

8. Hartmann S, Grandis JR. Treatment of head and neck cancer in the elderly. Expert Opin Pharmacother 2016; 17:1903-21.

9. Paydarfar JA, Birkmeyer NJ. Complications in head and neck surgery: a meta-analysis of postlaryngectomy pharyngocutaneous fistula. ArchOtolaryngol Head Neck Surg. 2006;132:67-72.

10. Sciubba JJ, Goldenberg D. Oral complications of radiotherapy. Lancet Oncol 2006;7:175-83.

11. Rothwell BR. Prevention and treatment of the orofacial complications of radiotherapy. J Am Dent Assoc 1987; 114:316-22.

12. Naidu MU, Ramana GV, Rani PU, Mohan IK, Suman A, Roy P. Chemotherapy-induced and/or radiation therapy-induced oral mucositis-complicating the treatment of cancer. Neoplasia 2004;6:423-31.

13. Lanzós I, Herrera D, Lanzós E, Sanz M. A critical assessment of oral care protocols for patients under radiation therapy in the regional University Hospital Network of Madrid (Spain). J Clin Exp Dent 2015;7:613-21.

14. Laan HP, Bijl HP, Steenbakkers RJHM, Schaaf A, Chouvalova O, Vemer-van den Hoek JGM, Gawryszuk A, van der Laan BFAM, Oosting SF, Roodenburg JLN, Wopken K, Langendijk JA. Acute 
symptoms during the course of head and neck radiotherapy or chemoradiation are strong predictors of late dysphagia. Radiotherapy Oncology 2015;115:56-62.

15. Fattore L, Rosenstein HE, Fine L. Dental rehabilitation of the patient with severe caries after radiation therapy. Spec Care Dentist 1986;6:25861.

16. Gupta N, Pal M, Rawat S, Grewal MS, Garg H, Chauhan D, Ahlawat P, Tandon S, Khurana R, Pahuja AK, Mayank M, Devnani B. Radiation-induced dental caries, prevention and treatment-A systematic review. National J Maxillofac Surg 2015;6:160-6.

17. Furness $S$, Worthington $H$, Bryan $G$, Birchenough $S$, McMillan R. Interventions for the management of dry mouth: topical therapies (Review). Cochrane Database Syst Rev. 2011;12:CD008934.

18. Andrews N, Griffiths C. Dental complications of head and neck radiotherapy: Part 1 . Aust Dent J 2001;46:88-94.

19. Claudy MP, Miguens SA Jr, Celeste RK, Camara Parente R, Hernandez PA, da Silva AN Jr. Time Interval after Radiotherapy and Dental Implant Failure: Systematic Review of Observational Studies and Meta-Analysis. Clin Implant Dent Relat Res 2015;17:402-11.

20. Hancock Pamela J, Epstein Joel B, Georgia Robins Sadler. Oral and Dental Management Related to Radiation Therapy for Head and Neck Cancer. J Can Dent Assoc 2003;69:585-90.

21. Kim JE, Kim NH, Shim JS. Fabrication of a complete, removable dental prosthesis from a digital intraoral impression for a patient with an excessively tight reconstructed lip after oral cancer treatment: A clinical report. J Prosthet Dent 2016;117:205-8.

22. Brennan MT, Shariff G, Lockhart PB, Fox PC. Treatment of xerostomia: A systematic review of therapeutic trials. Dent Clin North Am 2002;46:847-56.

23. Rius JM, Llobet LB, Soler EL, Farré M. Salivary Secretory Disorders, Inducing Drugs, and Clinical Management. Int J Med Sci 2015;12:811-16.

24. Byrne BE. Oral manifestations of systemic agents. In: ADA guide to dental therapeutics. Chicago: ADA Publishing; 1998:469-75.

25. Sreebny LM, Schwartz SS. A reference guide to drugs and dry mouth. Gerodontology 1986;5:7599.

26. von Bültzinglöwen I, Sollecito TP, Fox PC, Daniels $T$, Jonsson $R$, Lockhart $P B$, et al. Salivary dysfunction associated with systemic diseases: systematic review and clinical management recommendations. Oral Surg Oral Med Oral Pathol Oral Radiol Endod 2007;103:1-15.

27. Çağlayan F, Harorlı A, Çakur B. Tükürük bezlerinin radyografik muayene yöntemleri ve sialografi. Atatürk Üniv Diş Hek Fak Derg 2003;13:99-111.

\section{Yazışma Adresi}

Doç. Dr. Rukiye DURKAN

Afyon Kocatepe Üniversitesi Diş Hekimliği Fakültesi Protetik Diş Tedavisi Anabilim Dalı 05304152496

e-mail: rukiye_durkan@hotmail.com 